\title{
Correction to: Drought projection in the Indochina region based on the optimal ensemble subset of CMIP5 models
}

\author{
Rattana Chhin ${ }^{1,2,3} \cdot$ Chantha Oeurng $^{3}$ - Shigeo Yoden ${ }^{1,4}$
}

Published online: 27 November 2020

(C) Springer Nature B.V. 2020

\section{Correction to: Climatic Change \\ https://doi.org/10.1007/s10584-020-02850-y}

The original article has been corrected. Figure 3 in the original article has been replaced by this figure.

The online version of the original article can be found at https://doi.org/10.1007/s10584-020-02850-y

Rattana Chhin

rattana.chhin@gmail.com

1 Division of Earth and Planetary Sciences, Graduate School of Science, Kyoto University, Kyoto 606-8502, Japan

2 Research and Innovation Center, Institute of Technology of Cambodia, Phnom Penh, Cambodia

3 Faculty of Hydrology and Water Resources Engineering, Institute of Technology of Cambodia, Phnom Penh 12156, Cambodia

4 Institute for Liberal Arts and Sciences, Kyoto University, Kyoto, Japan 

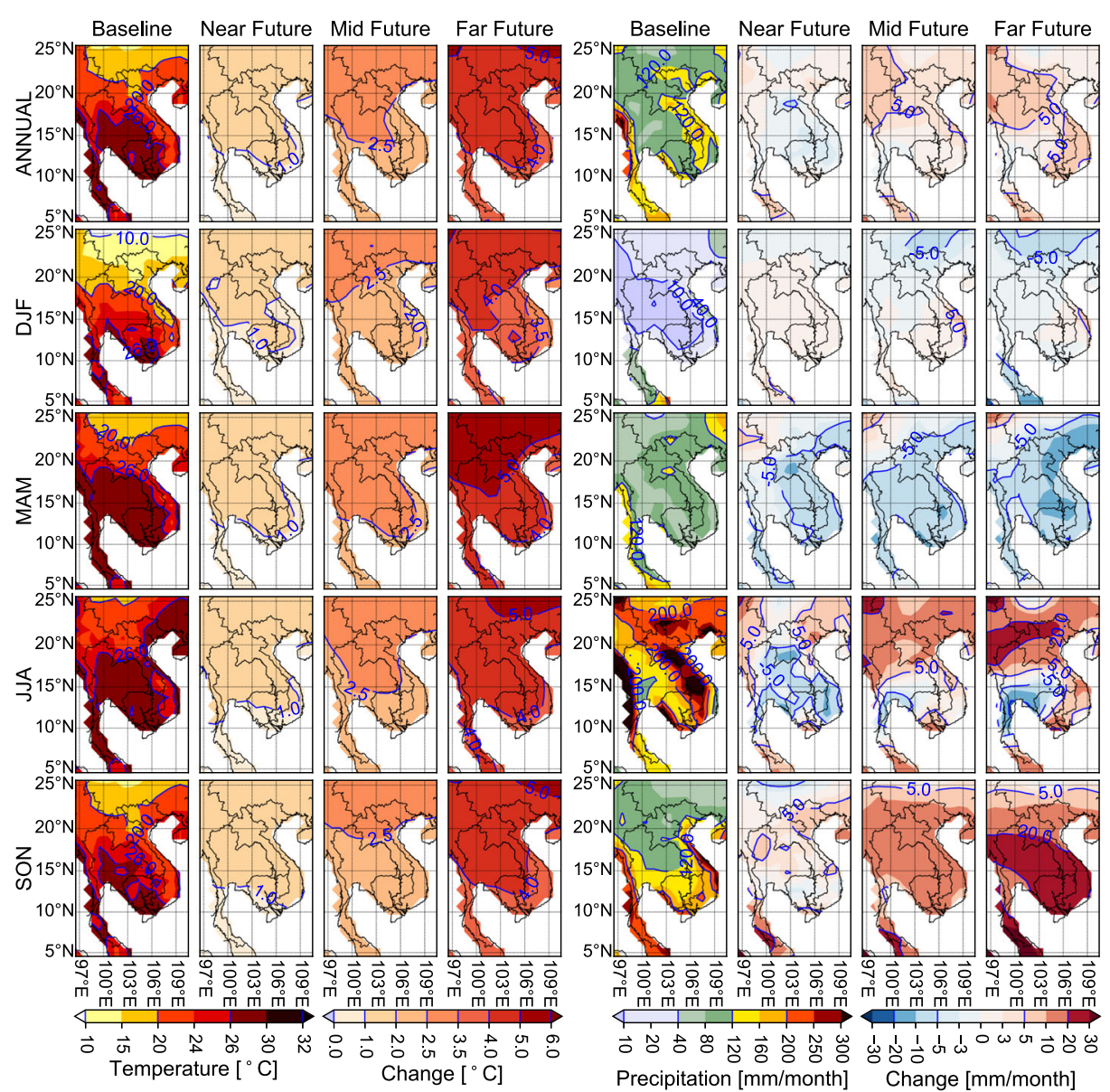

Publisher's note Springer Nature remains neutral with regard to jurisdictional claims in published maps and institutional affiliations. 